This is a preprint. Please cite the published article as:

Earvin Charles Cabalquinto \& Cheryll Ruth R. Soriano (2020) 'Hey, I like ur videos. Super relate!' Locating sisterhood in a postcolonial intimate public on YouTube, Information, Communication \& Society, 23:6, 892-907, DOI: 10.1080/1369118X.2020.1751864

\title{
'Hey, I like ur videos. Super relate!' Locating sisterhood in a postcolonial intimate public on YouTube
}

Earvin Charles Cabalquinito, Deakin University

Cheryll Ruth Soriano, De La Salle University-Manila

\begin{abstract}
This paper re-examines YouTube as a site of feminine, networked, and intimate sociality among Filipino women online. We unpack this by identifying how commenters on YouTube engage with the performativity of an intimate relationship between a Filipina and her foreign husband on YouTube. Extending Mina Roces' concept of 'local sisterhood' in the digital context, we coin the term 'online sisterhood' to articulate the diverse ways through which Filipino women engage with interracial intimacies in the realm online communication. By conducting a thematic analysis of comments on a popular YouTube channel of a Filipina married to a Caucasian man, we uncover the dimensions of an unfolding online sisterhood as aspirational, relatable, regulatory, and defensive modalities. We argue that these frames are informed by gendered, racialized, and even class-based aspirations and contestations tied to Philippine postcolonial history and society. Ultimately, as a site for feminine sociality and intimacy, YouTube also becomes a site for constructing, reinforcing as well as countering the stereotypical representations of Filipino women in a networked and postcolonial space.
\end{abstract}

Keywords: YouTube, Intimate publics, Online sisterhood, interracial relationship, Filipina

\section{Authors' Bio:}

Earvin Charles Cabalquinto, Ph.D. is Lecturer in the School of Communication \& Creative Arts, Deakin University, Melbourne, Australia

Email: earvin.cabalquinto@deakin.edu.au

Cheryll Ruth R. Soriano, Ph.D is Professor, Department of Communication, De La Salle University, Manila, Philippines

Email: cheryll.soriano@dlsu.edu.ph 


\section{Introduction}

Interracial marriages have been part of the Philippines social fabric. According to the Commission on Filipino Overseas (2018), 511,463 Filipinos who married foreign nationals between 1989 and 2018 were women. Philippine transnational marriages may appear to fit the pattern of brides from a poor country and grooms from richer ones, yet such migrations are often not only shaped by economic factors but also by racial geographies that have their own cultural logics (Constable, 2003). Aspirations for such partnerships are formed within colonial histories that privilege a particular form of colonial modernity and imaginary of romantic love (Constable, 2003, Lauser, 2008).

Simultaneous with this movement and mobility of Filipinos through marriage migration is the proliferation of digital communication technologies, which cater to creative performances of everyday life and engendering new connections. YouTube, one of the most highly subscribed social media platforms in the Philippines (WeAreSocial, 2019), has contributed to the broadcast of creative and personalized expressions. Considered one of the top markets for YouTube, the number of subscribers over the past three years increased by 20 times, while the number of channels with more than one million subscribers has increased 10 times from 2016 to 2019 (Mercurio, 2019).

The very idea of enabling oneself to utilize videos for personal and creative expression inspires divergences and cultural specificities in its appropriation. YouTube has brought into the public interest diverse creative content of cultural interest that were previously relegated to the intimate or private domain, such as beauty, eating, mothering, and other aspects of domestic and intimate life often shot through amateur 'home videos' (Burgess \& Green, 2009; Cunningham, 2012; Kumar, 2016). From its minority and alternative media roots (Jenkins, 2009), YouTube has given rise to a wide user-created content community, and is also now considered to be an important site for amateurs, micro-celebrities, small entrepreneurs, and even large companies to push their content for wide exposure and with monetary benefits. Yet, YouTube videos become the anchor for different forms of cultural and associational expression among diverse publics (Cunningham, 2012; Jenkins, Ford, \& Green, 2013; Nduhura, Kim, \& Mumpreze, 2019). Notably, although YouTube's architecture 
and interface is initially designed for individual participation rather than collective formation (Burgess \& Green, 2009, p. 63,65), it has now transformed into a communicative and interactive space among content creators (Lange, 2014; Burgess \& Green,2009, p. 65), as well as subscribers, fans, and visitors (Garcia-Rapp \& Roca-Cuberes, 2017; Lange, 2014). This exposition of intimate lives and networked interactions paves the way for a digital intimate public (Dobson, Robards \& Carah, 2018), although possibilities for the formation of this intimate public around the commenting community of YouTube users in a postcolonial context has yet to be fully explored.

This paper re-examines how intimate sociality, affinity and divergence are played out in the comments of individuals commenting on the YouTube videos of a migrant Filipina YouTuber ('Amanda', as pseudonym), who is married to a Caucasian man. Since 2012, our chosen YouTuber, Amanda, has amassed a following of more than 725 thousand subscribers and garnered over 85 million views. Her videos visibilize her everyday life, travels, as well as her intimate relationship with her Caucasian partner, which typically draws viewers and subscribers, as well as critics. She met her foreign husband through a dating website, which paved the way for her settlement overseas and eventually marrying her partner. To date, her YouTube channel offers over 1000 videos covering a variety of genres, including make-up tutorials, Q\&As, travels across various countries, among others. The YouTuber's videos typically receive diverse comments from viewers, serving as an anchor for enacting postcolonial and intimate commentaries.

This paper raises a set of inquiries on rethinking the textures of online engagement as these unfold in YouTube: What characterizes an intimate and online public in the realm of digital and postcolonial Philippines? What forms of feminine solidarities or contestations on the performativity of interracial marriages in the Philippines are generated on YouTube? How might influences of gender, race and class interfere in the production of commentaries? To address these questions, we deploy a thematic analysis of a random sample of 225 text comments (drawn from a pool of 7,549 comments) that were posted across the top five most viewed videos in her YouTube channel. 
One of the key contributions of this paper lies in extending Mina Roces' conception of sisterhood in the digital context, a proposition that also complements how female sociality, friendliness and solidarity is enabled by media spaces and texts in the western context (Kanai, 2019; Winch, 2013). Roces (2003) used the concept of 'sisterhood' to outline the 'female world' or the connection and solidarity forged among Filipino women migrants who are married to Australian men. Further, Roces (2003) deploys a postcolonial grounding to articulate the notion of local sisterhood as a symbolic kind of association that allowed women to draw from shared positive and negative experiences of being a migrant Filipino woman married to a white man in a predominantly white town. We build on this important work characterizing the everyday interactions where Filipino women share a sense of belonging through affective ties facilitated by experiences of othering while affirming their notion of self, femininity, and ideal romance. Sisterhood, we will argue, also surfaces in online spaces wherein women gravitate to each other based on trust, mutual experience, and parallel desires.

We coin the term 'online sisterhood' to articulate the networked, affective, feminine, and postcolonial dimension of online engagement among Filipino women around YouTube videos on interracial marriage. We will show that this 'online sisterhood' involves exchanges that are aspirational, relatable, regulatory, and defensive. Nevertheless, as to be presented in this study, online sisterhood indicates the reinforcement of imaginaries of an ideal subjectivity of a Filipina in an interracial relationship and crystallizes racialized and classed aspirations (and inequities) that are historically and socially entrenched. This proposition provides a critical understanding of online solidarities among women in the Philippines.

\section{Marriage migration, transnational mobilities, and migrant 'sisterhoods'}

The transnational mobility of Filipino women is often a direct result of an uneven distribution of different types of resources in Philippine society. Studies have shown how Filipinas have sought overseas migration in response to limited access to various capitals, social welfare services and work 
opportunities back home (Guevarra, 2010; Parreñas, 2001; Rodriguez, 2010). With former President Ferdinand Marcos' signing of the Labor Code of 1974, which formalized the promotion of overseas work as a stopgap measure in addressing the country's economic problems (Rodriguez, 2010), Filipino women found themselves working as domestic helpers (Parreñas, 2001), nurses or caregivers (Guevarra, 2010) as well as entertainers (Parreñas, 2011) across continents. In turn, migrant workers are glorified by the government as the country's 'new heroes' (Guevarra, 2010) who are recognized as good global service workers and dollar earners for the country. Tied to the export of service labor is the export of 'wives', or what was more commonly identified as the 'mail-order bride', a concept that has also been criticized by some scholars (e.g. see Constable, 2003)

The notion of a 'mail-order' bride pertains to a woman who seeks to marry a foreigner to alleviate one's socio-economic condition. Further, she is assumed to capitalize on affective, reproductive and sexual labor to access a stable future for herself and her left-behind loved ones in the Philippines. While media's sensationalist representations (Saroca, 2006) might highlight the victimization of brokered Asian wives as the subject of 'sexual exploitation' and 'forced labour', we will follow the stance taken by earlier works (Constable, 2003; Aquino, 2018; Espinosa, 2017) that examined the agentic aspects as well as postcolonial dimensions of Filipinas who seek to partner with foreign white men. Placing the analysis within a broader socio-historical analytical frame, for example, Constable (2003) argues that the 'cultural logic of desire' underpins Filipinas' preference for white male spouses. This logic has been fashioned out of a specific historical relationship between the United States and the colony, the Philippines, in which American cultural superiority and American benevolence provide the filters for Filipino women's marital preferences.

Anchored on aspirations of class and racial mobility, marrying a foreigner can imply migration to a 'better life', achieving stability for oneself and for left-behind family members as evinced in the flow of money transfers and material goods (Tolentino, 1996). Significantly, this mentality has been reinforced through a US-patterned education system, influencing Filipinos to learn about and look up to Western culture, practices, traditions, and systems as ideals (Tolentino, 
1996). Further, the Philippine colonial past has paved the way for the Filipino's hierarchical racial affinity (Rafael, 2000), where marrying a white, foreign national implies promises of class mobility entangled with a multitude of indirect social advantages, such as the possibility of living a better life, the promise of enriched social influence at home, or even bearing light-skinned, blue-eyed children.

Yet, the notion of the 'mail-order bride' carries local class and regional inflections. Locally, a distinction exists between Filipinas who seek to marry foreign nationals for money and those who find their white partners serendipitously through love, and where the former are assumed to come from lower-income localities or regions outside the capital Metro Manila. However, in foreign countries, and often due to media representations, the same prejudices are imposed on Filipinas partnering with white foreign men, regardless of how the women migrated or met with their partners (Saroca, 2006, p. 81-82; Cabañes \& Collantes, 2020). Often cast as 'commodity transactions', these relationships are perceived as 'akin to prostitution and devoid of romantic love' (Saroca, 2006, p. 82).

\section{Postcolonial and feminine intimacies on YouTube}

While the scholarly literature on YouTube in the West is growing (see for example Burgess \& Green, 2009; Lange, 2007), there remains limited scholarly work examining the multiple appropriations of YouTube in the Global South within its distinct context. We address this limitation by following the lead of some pioneering works examining the meanings and intimacies enacted by intersecting amateur and professional broadcasts on the site (see for example, Kumar, 2016). This paper examines a distinct form of postcolonial and feminine intimacy emerging from socialities afforded by the access and engagement with YouTube videos in relation to interracial marriage. Thus, following the lead of earlier works (i.e. Burgess \& Green, 2009), YouTube is not only examined here as a platform but as an intermediary of economic, political, and social goals and aspirational lifestyles. We approach YouTube as a space where social interactions and connections are established among users as well as commenters (Burgess \& Green, 2009). The broadcast of the vernacular and everyday 
performances does not only allow peer exchanges and learning (Burgess \& Green, 2009). Online performativity also serves as prompts in interactions, affinities and critiques among online users (Lange, 2014). In this regard, we explore in-depth how YouTube becomes a site for the construction of intimate publics that are bound by relatability, romantic aspirations, and the affective and cultural tensions surrounding public broadcast of an intimate domestic life.

There is growing research on the role of digital media in shaping notions of intimate publics. In the first instance, the conception of 'public' refers to both a highly accessible space where wide audiences can gather and a collection of people who share a 'common understanding of the world' (boyd, 2010, p. 39). Public lives are then entangled with the advent and widespread uptake of digital communication technologies and social media channels. In a networked environment, individuals utilize a variety of social media activities, such as storytelling and videocasting to create affect worlds which express their personal stories and foster emotional connections. These online content creations pave the way for the formation of intimate publics (Berlant \& Prosser, 2011; Morrison, 2011). The performative use of images and videos in social media are also understood to facilitate networked intimacies (Dobson, Robards \& Carah, 2018) and visual intimacies (Miguel, 2016) that also bridge the online and offline and private and public. Important to consider in these formations and productions of intimacy is the subjectification process involving the 'hierarchical ordering of relationships and psychic concerns' that help people make sense of the self and those around them (Dobson, Robards \& Carah, 2018, p. 1). We examine online engagements, affinities, and contestations by paying close attention to the reactions to a Filipina who broadcasts her interracial relationship on YouTube. Yet, even as we examine intimacies among Filipino women on YouTube, we examine such intimacies as tied to the dynamic flows of global modernity.

We build on existing work that uncovered how female audiences and producers of digital media interact with and interpret media texts, highlighting historically and politically constructed meanings attached to texts (Kanai, 2019; Winch, 2013; Soriano, Lim \& Rivera, 2016). For instance, media texts often utilize the intimate rhetoric of belonging and recognition to encourage women and 
young girls to improve themselves, participate in homosocial connections, as well as constantly surveilling and regulating others (Winch, 2013). In the context of digital media, online spaces such as forums serve as sites to discipline oneself and others and achieve a self-replenishing and entrepreneurial self (Winch, 2013). Winch (2013, p. 5) argues that women watch other women through a 'girlfriend gaze' to mobilize the body and the aspiration to achieve an ideal femininity, as a 'gynaeopticon' (Winch, 2013, p. 9). This reading problematizes online 'girlfriendships' and intimacies around femininity as attached to norms of discipline and surveillance (Winch, 2013).

This paper does not only engage with a gendered lens in examining interactions on YouTube. It also explores femininized sociality with 'postcolonial intimacies' (Antwi, Brophy, Strauss, et.al., 2013), which foregrounds 'the epistemic decolonizing potential among postcolonial subjects in turning to affect as a basis of exploring injustice' (p. 2). Carrying an interventionist orientation, postcolonial intimacies disrupt available historical scripts and retexture intimate archives of content among people outside the purview (although not necessary of control) of formal institutions of the State (Antwi, et al, 2013, p. 4). As we will show in the findings, postcolonial intimacies can engender intimate and affective exchanges that serve to function to simultaneously normalize and challenge the prejudices around Filipino women seeking foreign partners. In doing so, we coin the term 'online sisterhood' to articulate how online engagements create solidarities and tensions among users who engage with socio-historically entrenched representations of gendered, racialised and classed bodies in interracial relations.

\section{Methodology}

This paper involved a close reading and thematic analysis (Flick, 2011) of a random sample of 225 text comments (drawn from a pool of 7,549 comments) that were posted across the top five most viewed videos in a YouTube channel run by Amanda, who is a lifestyle, beauty and Filipina YouTuber, and married to an Caucasian man. Following the ethical guidelines of the study, we used the name 'Amanda' to replace the real name of the YouTuber. The five videos present the intimate encounters 
of Amanda with her husband, including their love story, their wedding day, food preparation for the family, affectionate moments, and plans on having a baby. Using a thematic analysis of comments, we conducted a close reading of each comment and deployed an open coding, a process involving the segmentation and close reading of comments (Flick 2011). We categorized and analyzed the data (Creswell, 2013) from June to September 2019. Initially, we identified comments that are affirmative (generally positive towards the performativity of the YouTuber), contradictory (generally criticizing the performativity) and irrelevant (comments that do not relate to the performativity) to the videos. We then employed selective coding (Flick, 2011), elaborating some of the emerging themes in the initial categorization of comments. Conducting a critical analysis of the comments unraveled the tropes that reflected affirmations and contestations of practices, expectations and norms in an online channel (García-Rapp \& Roca-Cuberes, 2017; Lange, 2014). It is through such a process that we arrived at identifying the salient categories of comments on YouTube, including aspirational, relatable, regulatory, and defensive.

Table 1. Selected videos of Amanda.

\begin{tabular}{|l|l|l|}
\hline VIDEO TITLE & VIEWS & COMMENTS \\
\hline Video 1. Wedding Day & 939,686 & 2,558 \\
\hline Video 2. Cooking for the family & $1,548,391$ & 1,656 \\
\hline Video 3. Husband shows affection & $1,024,690$ & 1,092 \\
\hline Video 4. Love story & 895,110 & 1,422 \\
\hline Video 5. Plans of having a baby & 911,039 & 821 \\
\hline
\end{tabular}


The conduct of the study observed a de-identification process as part of the ethical considerations of data collection ${ }^{1}$. Following the ethical decision-making and recommendations of the Association of Internet Researchers' Ethics $(2012,2019)$, we reflected upon the careful handling, documentation, analysis, and presentation of publicly accessible data. While we did not obtain consent from the YouTuber and the commenters of the video, we took extra precautions in protecting the privacy of the YouTuber and the user's comments on the videos. First, we deidentified the YouTuber by using a pseudonym. We used the name 'Amanda' as a substitute for the real name of the YouTuber. Second, we used a generic title for her videos. Third, we used a pseudonym for the YouTuber's husband. Fourth, we omitted the usernames for the users who commented on the videos by using terms, including 'a commenter', 'another commenter, and so forth. The comments were extracted in May 2019 through a free online tool YouTube Comment Scraper. Lastly, we used the pseudonym of the YouTuber ('Amanda') and her husband ('John') whenever their names were mentioned in the comments and omitted references to nationality, place and a dating website. Ultimately, we adopted previous strategies on de-identifying commenters on YouTube to employ an ethical approach in accessing, analyzing and presenting data, including omitting the commenters' username (García-Rapp \& Roca-Cuberes, 2017) or using generic labels (Lange, 2014).

As we are particularly interested in determining how Filipino women engage with the selected videos, we relied on linguistic cues to identify the gender and nationality of the video commentators. The gender of some of the commenters was identifiable through comments, such as "My husband is also...". The use of 'Ate' a local term for elder sister, was also often engaged, indicating the commenter is a Filipina. In many instances, the women were commenting in mixed Filipino-English (colloquially called 'Taglish'). We also noticed the use of the word 'Sis'. Locally, the word 'sis' is a recognition of affiliation among women, not necessarily by blood, but by some other

\footnotetext{
${ }^{1}$ The research study followed the guidelines of the Deakin University's Human Research Ethics Committee (DUHREC) (project number 2018-264).
} 
common ground or interest. It is worth noting that we are not interested in conducting a network analysis of comments and online interactions, such as paying attention to who are commenting and interacting frequently. Rather, interactions were examined closely to understand the characteristics of 'sisterhood' unfolding in these videos. Included in this paper are selected quotes which were translated from a mix of Filipino and English to English. The commenter's profiles were de-identified to protect their privacy.

\section{Filipina Sisterhood on YouTube}

Sisterhood emerges through the networked space of YouTube, wherein the YouTuber acts as an intermediary of positive feelings and even unsettling emotions. The comments reflect how gendered and racialized forms of solidarities indicate the diverse, competing and often hierarchical views on the positionality of a Filipina in an interracial marriage. We characterize online sisterhood as a networked and affective modality involving aspirational, relatable, regulatory, and defensive characteristics.

\section{Aspirational}

The first dimension of online sisterhood is labelled 'aspirational', pertaining to how commenters perceive the YouTuber as a role model for being in an interracial relationship. For instance, when Amanda detailed how she met her husband through a dating site in one of her videos, several commenters considered the story 'nakakakilig' or drawing emotional elation. This affective resonance in an online space shows that individuals tend to live vicariously in the spectacle of a romantic interracial relationship.

The word 'Ate' was often used by several comments to address Amanda, relating to an elder sister in Filipino language, but which may pertain to either a sister by blood, or a form of addressing another Filipino woman with respect and affinity. Further, the term carries an expectation that what the 'Ate' has achieved in life is worth following or emulating. This point echoes how the 'big sister' 
persona, as crafted through performativity of expertise and skills online, becomes an anchor for engagement among viewers (Berryman \& Kavka, 2017). By closely examining the comments, 'Ate' is appropriated to establish a fictive familial connection and positions '(Ate) Amanda' as a particularized role model for an interracial relationship. This point is reflected in the quote from one of the commenters : 'Ate Amanda, I hope I can also find someone like Kuya John. Where can I create an account in a dating website? Please help me. I hope that someday I can find a foreigner in my life' In some cases, there were comments that showed aspirations reflecting intersecting gender and ethno-linguistic affinity. In here, what the 'Ate' has achieved in life is not only seen as a traditional Filipina construct, such as being caring and family oriented. There is also an element of being able to relate to the YouTuber's ethnic background, which then becomes a symbol of one's pride. As a commenter excitedly writes,

I LOVE YOU ATE AMANDA. It's my first time to see your vlogs and I really really love it like woaaaah. I was so amaze and I enjoy a lot and it's truly inspire me on my future. What a nice and wonderful love story, Ate. Can't stop watching your vlogs. You're right Ate, that love truly waits for those who are willing to wait. We should not trust people easily especially kung puro lang compliments (If everything is a compliment.). A big thumbs up for this. Me and my friends are very amazed watching your vlogs... I'm so proud of you kay imo jung gipa taas ang bandera sa mga bisaya hahaha. Lahi ra jud ang atong beauty ate (/ am proud of you because you represent us very well. We are beautiful people). I love you ate Amanda and keep going. God bless you and to your husband.

Amanda's YouTube videos often pan around their home. These visual cues of their marital home located in an economically developed country - modern, beautiful and spacious by Filipino standards-along with a regular display of purchased items, gifts received from her husband, or expensive food from the fridge, serve as visual cues that also trigger comments of both pride and aspiration, 'ang swerte mo, sis!' (You are so lucky, sis!), again this good fortune is tied to having been able to marry a foreign husband and achieving a comfortable life. 
Amanda's videos also attract aspirational comments reflecting that the women's standards of beauty or good life is tightly connected to racial hierarchies. For instance, in one of her videos, Amanda was shown asking her husband about their plans on having a baby. For some commenters, the narrative feeds the desire of having a mixed-race baby: 'Ang gwapo ng hubby mo, Sis. pag magkaka baby kau sure ako sobrang ganda or gwapo yan' (Your husband is so handsome, sis. I am sure the baby will be very pretty or handsome.) This reflects the valorization of having a mixed-raced baby, which is deemed as a marker of a successful family life given the high regard ascribed to mixed-race or mestizo child (Rafael, 2000).

In some instances, aspirations indicate a reminder of one's living condition, which is often impacted by socio-economic and socio-political conditions in the Philippines. In one of her videos, Amanda was seen relaxing while being cared for by her husband, including preparing breakfast for her and attending to her other needs. In another scene, she receives a peck on her chin from her husband as she wrapped a birthday present. Such intimate and playful moments generate a reflective response:

This is such an adorable one. :) I've always wanted to have a white boyfriend too. I joined dating sites before and every time I speak with someone I immediately told him that I am an OFW and comes along with that is, I travel to different countries every 6 months. And that some could not understand. Fall out is how it ends. I giggled whenever I watch a Filipinaforeigner blogs. It's amazing how these guys show care to their Filipino wives. They are like teddy bears that their wives love to cuddle. PS. Amanda you're so pretty sis.

In this comment, we can see a particular identity marker of an OFW or an Overseas Filipino Worker, which essentially symbolizes one of the tropes of feminized labor export in the Philippines (Parreñas, 2001). As reflected in the comment above, the demands of overseas work may take a toll on Filipino women who are thinking of settling in a romantic relationship. Amanda's depiction of a 'beautiful life' as a YouTuber married to a Caucasian man and who is affectionate towards her, therefore, sets up a glaring contrast with the conditions of other Filipinas who are also based overseas, but 
performing the drudgery of overseas work. For some of these Filipinas who seek to work overseas, the quote above speaks to the aspiration of not only finding a job but finding a loving and understanding foreign husband. Thus, these workers look up to and aspire to be like Amanda, who appears to effectively embody their aspirations.

The sisterhood would also often praise Amanda's vlogging style,

I really don't know nganu cgeg nako watch sa imong videos ... Pero iwan! namamagnetize ako... (I really don't know what attracted me to your videos, but I am magnetized!) Pero seriously speaking... nakakagaan lang panoorin videos mo! Very natural kasi unlike ung iba very scripted. (I feel relaxed when I watch your videos. Because it is very natural unlike others that are very scripted.) I even clicked the bell button. Para nanonotify ako pag may bagong videos (so I can be notified when you have new videos). You rock gurl!

Other commenters would request Amanda to share vlogging tips so that they could emulate her and develop their own vlogs. We argue that as reflected in these comments, the vlogging style also functions to generate affect and a sense of attachment to the vlogger and her vlogs that facilitates continued subscription and engagement, allowing the enactment of these feminine and racialized intimacies.

\section{Relatable}

The second dimension of online sisterhood highlights how Filipino women 'relate' to the narratives of the video. In this paper, relatability is operationalized by how Amanda visibilizes her everyday and intimate relations with her foreign husband. Some of the commenters highlight their similar experiences in an interracial relationship. For instance, in her love story video, Amanda talks about meeting her foreign partner through a dating website. This narrative inspired the commenting community to reflect on interracial relationships:

OMG. I LOVE how you talk about the start of your relationship Ate Amanda and relate ako in some parts coz i'm also dating a foreigner right now and sa online dating site ko din cya 
nakilala (We also met through a dating site) \& almost 1 year na kami laging magkausap (We have been talking for more than a year already) \& super bait nya (He is very kind) \& he makes me happy \& also he respects me. But wla pang official date kung kailan kami magkikita kasi (there's no official date yet when we will meet in person because) he's from [European country, omitted] and we're both busy pa but excited nako kasi napapagusapan na naming yung pagkikita naming (I am very excited to talk through our meet up). Hopefully talaga we will end up together and nung katulad sa inyo na okay na okay yung pagkikita (Hopefully we end up together just like you and your partner). God Bless sa inyo ate Amanda. Stay strong to the both of you.

In the same video, Amanda highlights her strategies for finding a respectable man on a dating website. She narrates how she uploaded wacky photos instead of posting sexy images in order to find someone who will accept and like her funny personality. For some commenters, this act is commendable:

I get you. I understand you perfectly. I met my husband [nationality omitted] through the dating site and all stuff (we have the same situation back then. I put an 'ugly' photo, not talking to rude men, and then I met a decent and respectful hubby. After that the story changed in a good way. I'm happily married with a one-year old baby girl.

Connected to this trope of relatability is where Amanda's videos serve as a guide for some Filipino women in managing an interracial relationship. As one comment shows, "Hey! I like ur videos! super relate! I always think people's opinion about us. I was like 'Itutuloy ko ba ang pogcocommunicate sa knya or nah?' (Should I continue communicating with him?) I think I need to know him more... But thanks to this video". In here, the content may provide advice and guidance echoing the role of vloggers in providing tips and tricks among online audiences (Berryman \& Kavka, 2017).

We found that Amanda's YouTube videos become the focal point for attracting other Filipinas in a similar situation, whether seeking to find or already engaged in romantic relationships with foreign men. As comments expressing 'relatability' some commenters also reveal how Filipinas 
sought to challenge the stereotypical representation of Caucasian men and the nature of their relationship with Filipinas, that which is connected to the transactional nature of the 'mail-orderbride' trope. Previous studies have shown how Caucasian men in this relationship have been constructed as the financially stable other who 'purchase' Asian women (often the financially dependent one) through an online website (Constable, 2003), and which then represented Filipinas as marrying for money and not out of love. Amanda's video drew comments seeking to challenge this trope, for example:

In my case I have a boyfriend from abroad who is graduating with a six-digit loan. He's a country guy, they're not rich but I love him so much because he's just simply amazing and he loves me so much. He was the one who's asking me for a loooong time to migrate to [country omitted] but I was the one who doesn't want to move out of the country. What he did was he talked to my family and asked for their blessing about taking me abroad after we got married, appreciated his effort, I agreed but I told him I want to graduate first so he's gonna wait for me and I told him that when I'm already working I'Il help him settle his debts.

\section{Regulatory}

Friendliness is one of the key dimensions of online sisterhood. However, friendliness can also become a tool for the construction and regulation of certain practices and values of women in obtaining idealized femininities. Here, the girlfriend gaze (Winch, 2013) is operationalized to scrutinize and primarily control the performativity of a gendered body that in turn tends to reinforce patriarchal ideologies. Rather than highlighting practices that produce a self-replenishing or entrepreneurial self (Winch, 2013), the gaze of the commenters tends to articulate a type of Filipina that is a wife material or one who can deliver well in household chores. The YouTuber also becomes a project that is under construction and in constant transformation (Winch, 2013), which commenters may play a role in the process of transformation. For instance, in one of her videos, Amanda shows how to cook chopseuy for her in-laws. Chopseuy is a vegetable dish garnished with 
meat and eggs and bound in a starch-based sauce. We noticed that Amanda's video attracted many suggestions from commenters on how to cook or add variety to the dish, all with the seeming intent of helping Amanda become a good cook, and a good wife. While some commenters suggest adding different ingredients, others suggest what the best Filipino recipes would be to please the foreign husband. Other comments emphasize that she observe proper hygiene in cooking, as a marker of a skillful, discerning, and ideal wife. In videos where Amanda would show care in cleaning the house or preparing home meals for either her husband or his family, commenters would say, 'Oh my this is the real filipina values, a good wife, and a very good daughter. Masipag at mapagmahal' (hardworking/attentive, and loving) or 'ur a good image of true filipina!'. Friendliness is thus being observed in online interactions. However, such polite and suggestive banters reflect that while viewers watch her videos, they are judging her actions in relation to their ideals of a good Filipino woman or a good wife and can be interpreted as generating regulatory and positive affect. This point echoes how women watch other women through girlfriendly spaces and banters (Winch, 2013). Ultimately, the commenters contribute in the production of an idealized Filipino wife, who is caring, responsible and domesticated even in an interracial relationship.

\section{Defensive}

As a final and important dimension, the online sisterhood unfolds with a defensive characteristic, which also emerges as a response to disruptive and even derogatory comments directed at the YouTuber or the ideals that she advances. Although commenters connect to Amanda given the commonality of aspiration or experience, this connection also triggers strong criticisms based on a racialized and class-based interpretation. The public display of her everyday life "means setting oneself up for scrutiny and analysis by the 'gynaeopticon'"' (Winch, 2013, pp. 5, 160), and these involve both supportive and antagonistic comments. Winch (2013) describes the 'gynaeopticon' as a gendered, neoliberal version of Bentham's panopticon involving how women bond around the scrutiny of other women that manifest as 'homosocial forms' and 'affective networks of control' (pp. 
5, 18-20).In one of her videos, Amanda talked about her main purpose of signing up on a dating website, which is to speak to someone and vent her personal problems. Such a 'bold confession' (Raun, 2018), a form of positioning oneself as authentic in an online space, was criticized by some commenters. The word 'hyprocite' was salient in the comments.

Grabe nag-sign up sa [site omitted] para lang maghanap ng makakausap (Wow you signed up to speak with someone). Wala ka bang friends and family bakit sa stranger pa? (Don't you have friends and family? Why hook up with a stranger?)... Just don't be hypocrite and show your real self.

I found her hypocrite too. Gusto nya lang pumunta sa dating site para may kausap (She used the dating site so she can speak to someone). What? U have friends and family but she preferred stranger for comfort. Why so ashamed to tell that $u$ signed up in the site just because u wanted to marry a foreigner, be in his place, fulfil your dreams, and boast.... Too much hypocrisy.

The criticisms on Amanda's video reflect the stigma against Filipino women in an interracial relationship. This point echoes a cohort of studies that have unraveled discrimination towards Filipino women married to Caucasian men (Aquino, 2018; Constable, 2003; Espinosa, 2017; Lauser, 2008). In this research, we noticed that Amanda was also referred to as 'Inday' in several comments. The term 'Inday' is used to refer to women coming from the Visayan region of the Philippines. It is also sometimes used to refer to dark-skinned women who come from a poor economic background. By closely examining the comments, the word 'Inday' becomes a discriminatory term as it labels a Filipino woman from the regional areas wanting to marry a non-Filipino man, and usually white, for upward mobility.

Etong inday na to! (This Inday!) gusto mo lang makahanap ng foreigner para makaahon sa buhay at makatira sa ibang bansa! (You just want to find a foreigner to escape poverty and live overseas) at ngayon natupad na mga pangarap ni inday nkatira ka na sa [foreign land]! 
(And now Inday's dream is fulfilled as she's now in living in a foreign land [country concealed]. congrats!

I agree kung mayaman ka hindi ka makikipagsapalaran sa ibang bansa (I agree that you don't have to take risk and live overseas if you're rich)....Ang tutuo diyan gusto nilang makaahon sa hirap (The truth is they just want to escape poverty). Ang babaw na dahilan na kaya ka nag sign up para May kausap ka At Hindi mabored (A shallow reason of getting bored and signing up to a dating website). Don't be hypocrite! Ang daming mga inday [place omitted] na mga hypocrite (There are so many Inday who are hypocrite). Karamihan mga caregiver at ang iingay pa! (Most of them are caregivers and they are very noisy!).

In some instances, Amanda is compared to other 'Indays'. Drawing from prejudices based on class and ethnicity, the commenter looks down on Amanda, as she is compared to caregivers who make loud noises and indicate a low-class background. In sum, this trope represents pre-existing discrimination of Filipino women, framing them as marrying men from developed countries for pure monetary or economic value (Constable, 2003). To interpret this trope, we engage Winch's (2013) notion of girlfriendships that is also characterized by rivalry and greed as they facilitate notions of solidarity and affirmation.

Yet, we also highlight that it is in the presence of this scrutiny by other spectators, which can be expected in this mediated public self-presentation, that an online sisterhood of defense may manifest. Strikingly, the sisterhood speaks back to the discriminatory remarks towards Amanda through defensive comments. Examples of these defensive comments are shown below, where commentators also engage the trope of relatability to defend Amanda by showing proof of their own experience.

I was also a member of $\mathrm{A}$ (the name of the dating website, omitted) before and to say that Amanda is hypocrite when she said na gusto nya Ing kausap (that she just wants to talk to 
someone) is judgmental. Ako $[I]$, I also joined A to find someone I can talk to whenever I feel lonely and bored. Yes, I have friends around me, pero iba rin minsan ung feeling pag stranger ung kausap mo (but it is also a different feeling if you speak to a stranger). It's actually refreshing. Not everyone who joins a dating website are actually looking for a husband or they're there just to flirt. [...]

Love your story. I feel you ms. Amanda, other's here don't know the meaning of "hindi ka naghahanap" (You are not looking for someone) over "naghahanap ng kausap because you are broke" (You are looking for someone to talk to because you're broke). I know that feeling because we are the same situation but you are true that the love will come on you in an unexpected way. Me in my case I found my love at dating site and we are happy as of this moment. Just keep it up ms. Amanda don't let others down you just because we choose a "foreigner man". Godbless.

\section{Conclusion}

One of the key affordances (boyd, 2010) of YouTube is enabling geographically dispersed and diverse audiences to coalesce and engage in the display of a YouTuber's intimate and personal life. Such communicative affordances demonstrate how interactivity paves the way for an intimate public. In this paper, we have presented how Filipino women use commenting as a modality in fostering a sense of solidarity and sisterhood. This particular bond online is both operationalized through the affordances of YouTube and the enactment of postcolonial fantasies and desires. We demonstrate how online sisterhood involves four dimensions that are tied to how Filipino women are positioned in interracial relations within a postcolonial frame. In the first instance, Filipino women generate aspiration and relatability as informed by the logics of postcolonial desire - to be with a Caucasian partner or even bear a mixed-race child. Commenters also deploy friendliness to articulate and regulate the formation of an ideal Filipina wife and woman, as reflected in prescriptions of improving 
one's domestic capabilities. However, other Filipino women undermine the YouTuber's positionality in a relationship by stereotyping a gendered, ethnic and class-based identity. We refer to this as a form of disruption which draws strong defensive comments from the online sisterhood. Ultimately, YouTube does not only provide the visibility of the everyday and intimate life of a Filipina and her Caucasian husband. It facilitates a space where commenters demonstrate affinities and contestations of an interracial arrangement between a Filipina and a foreigner.

Notions of feminized connections and solidarities have been presented in the Western context, often enabling the performance of an independent, self-replenishing and entrepreneurial subjectivity (i.e., Winch, 2013). This paper highlights the character of gendered solidarities molded by postcolonial conditions in the Global South. Certainly, YouTube facilitates the broadcast and visibilization of interracial intimacies, which fosters imaginaries of an ideal Filipina wife as well as a good life. Women who are in the same position may applaud such conditions as 'empowering' or 'inspirational' within specific frames. Paradoxically, online performativity and the intimate connections it generates become a site of ambivalence for women (Kanai, 2019; Winch, 2013). As presented, while online sisterhood presents ways of generating intimate connections and sociality among Filipino women who aspire, relate or wish to be in an interracial relationship, it also perpetuates certain tropes of feminized bodies in a patriarchal and postcolonial reality. Here, the idealized Filipina or as one of the commenters said, 'wife material', who is typically caring, loving, an expert in household chores, or a bearer of a mixed-race child, is reinforced. This shows how domination and stringent gendered structures are internalized even in networked spaces.

In conclusion, YouTube has provided a unique space to display the intimate, playful and often personalized interaction between a Filipina and her Caucasian husband. However, it also generates interactions and connections that are often shaped by one's gendered, racialized and classed backgrounds. By examining how commenters engage with interracial relationships on YouTube, we locate how the concept of sisterhood (Roces, 2003) manifests in a digital space. Through YouTube's temporal and spatial affordances, Filipino women across the world can react and 
comment, often stirring friendly connections, and a sense of affective belonging as well as persistent regulation. Nevertheless, it is by unpacking the messiness and contradictions in an online space that we argue for a closer evaluation of the role of online sisterhood in perceiving, constructing and positioning Filipino women in a postcolonial and digital society. 


\section{Acknowledgement}

We would like to thank the two anonymous reviewers for providing sincere and critical feedback in strengthening the key arguments of the study. We would also like to extend our deepest gratitude to the Special Issue editors, Jonathon Hutchinson and Mary Elizabeth Luka, for their valuable assistance in the completion of the article. 


\section{References}

Antwi, P., Brophy, S., Strauss, H., \& Troeung, Y.-D. (2013). Poctcolonial intimacies: Gatherings, disruptions, departures. Interventions, 15(1), 1-9. doi:10.1080/1369801x.2013.770994

Association of Internet Researchers. (2019). Internet Research: Ethical Guidelines 3.0 Retrieved 10 January 2020, from https://aoir.org/reports/ethics3.pdf

Association of Internet Researchers. (2012). Ethical Decision-Making and Internet Research: Recommendations from the AoIR Ethics Working Committee (Version 2.0). Retrieved 12 January 2020, from https://aoir.org/reports/ethics2.pdf

Aquino, K. (2018). Racism and Resistance Among the Filipino Diaspora: Everyday Anti-racism in Australia. London and New York: Routledge.

Berlant, L., \& Prosser, J. (2011). Life writing and intimate publics: A Conversation with Lauren Berlant. Biography 34(1), 180-187. doi:10.1353/bio.2011.0008.

Berryman, R., \& Kavka, M. (2017). 'I Guess A Lot of People See Me as a Big Sister or a Friend': The role of intimacy in the celebrification of beauty vloggers. Journal of Gender Studies, 26(3), 307-320. doi:10.1080/09589236.2017.1288611

boyd, d. (2010). "Social network sites as networked publics: Affordances, dynamics, and implications." In Papacharissi, Z (ed.), Networked Self: Identity, Community, and Culture on Social Network Sites (pp. 39-58). New York: Routledge.

Burgess, J., \& Green, J. (2009). YouTube: Online Video and Participatory Culture. Cambridge, UK: Polity Press.

Cabañes, J.V.C \& Collantes, C. (2020). Dating apps as digital flyovers: Mobile media and global intimacies in a postcolonial city. In Cabañes, J.V. \& Uy-Tioco, L. (eds). Mobile Media and Social Intimacies in Asia. Reconfiguring Local Ties and Enacting Global Relationships (pp. 97-114). Dordrecht: Springer.

Commission on Filipino Overseas. (2018). Statistical profiles of spouses and other partners of 
foreign nationals. Retrieved 27 November 2017, from

https://www.cfo.gov.ph/downloads/statistics/statistical-profile-of-spouses-and-other partners-of-foreign-nationals.html

Constable, N. (2003). Romance on a Global Stage: Pen Pals, Virtual Ethnography, and

"Mail-Order" Marriages. Berkeley: University of California Press.

Creswell, J. W. (2013). Qualitative Inquiry and Research Design: Choosing Among Five Approaches

(3rd ed.). Thousand Oaks: Sage Publications.

Cunningham, S. (2012). Emergent innovation through the coevolution of informal and formal media economies. Television \& New Media, 13(5), 415-430.

Dobson, A. S., Robards, B., \& Carah, N. (2018). Digital intimate publics and social media: Towards theorising public lives on private platforms. In A. S. Dobson, B. Robards, \& N. Carah (Eds.), Digital Intimate Publics and Social Media (pp. 3 - 27). Switzerland: Palgrave Macmillan.

Espinosa, S. (2017). Sexualised Citizenship: A Cultural History of Philippines-Australian Migration. Gateway East, Singapore: Palgrave MacMillan.

García-Rapp, F., \& Roca-Cuberes, C. (2017). Being an online celebrity: Norms and expectations of YouTube's beauty community. First Monday, 22(7), 1-1. doi:10.5210/fm.v22i17.7788 Guevarra, A. (2010). Marketing dreams, manufacturing heroes: The transnational labor brokering of Filipino workers. New Brunswick: Rutgers University Press.

Flick, U. (2011). Introducing Research Methodology. Great Britain: SAGE Publications Ltd. Jenkins, H., Ford, S. and Green, J. 2013. Spreadable Media: Creating Value and Meaning in a Networked Culture. New York: NYU Press.

Jenkins, H. (2009). What happened before YouTube. In Burgess, J. \& Green, J., YouTube: Online Video and Participatory Culture. (pp. 109-125). Cambridge: Polity. 
Kanai, A. (2019). Gender and Relatability in Digital Culture: Managing Affect, Intimacy and Value. Basingtoke: Palgrave Macmillan.Lange, P. G. (2007). Publicly private and privately public: Social networking on YouTube. Journal of Computer-Mediated Communication, 13, 361 - 380.

Kumar, S 2016, 'YouTube nation: Precarity and agency in India's online video scene', International Journal of Communication, 10, 5608-25.

Lange, P. G. (2014). Commenting on YouTube rants: Perceptions of inappropriateness or civic engagement? Journal of Pragmatics: An Interdisciplinary Journal of Language Studies, 73, 53 65. doi:10.1016/j.pragma.2014.07.004

Lauser, A. (2008), Philippine women on the move: Marriage across borders. International Migration, 46: 85-110. doi:10.1111/j.1468-2435.2008.00473.x

Mercurio, R. (2019). Philippines among top markets for YouTube. Philstar Global. Retrieved from https://www.philstar.com/business/2019/07/28/1938388/philippines-among-topmarketsyoutube

Miguel, C. (2016). Visual intimacy on social media: From selfies to the co-construction of intimacies through shared pictures. Social Media + Society. https://doi.org/10.1177/2056305116641705 Morrison, A. (2011). Suffused by feeling and affect: The intimate public of personal mommy blogging. Biography, 34(1), pp. 37-55

Nduhura, D. Kim, S.D., Mumporeze, N. (2019). When Social Media are Your Sole Life Jacket":sLepiA Capability Analysis of Foreign Brides' Empowerment by Social Media in South Korea. OMNES : The Journal of Multicultural Society, 9(1), 148-184, http://dx.doi.org/10.14431/omnes.2019.01.9.1.148

Parreñas, R. S. (2001). Servants of globalization: Women, migration and domestic work, Standford, California: Standford University Press.

Parreñas, R. S. (2011), Illicit Flirtations: Labor, Migration and Sex Trafficking in Tokyo, Standford: Standford University Press.

Rafael, V. (2000). White love and other events in Filipino history. Durham: Duke University Press. 
Raun, T. (2018). Capitalizing intimacy: New subcultural forms of micro-celebrity strategies and affective labour on YouTube. Convergence, 24(1), 99 - 113.

Roces, M. (2003). Sisterhood is Local: Filipino Women in Mount Isa. In N. Piper \& M. Roces (Eds.), Wife or worker? : Asian women and migration (pp. 71 - 100). Lanham, MD: Rowman \& Littlefield.

Rodriguez, R. M. (2010). Migrants for Export: How the Philippine State Brokers to the World. Minneapolis: The University of Minnesota Press.

Saroca, C. (2006). Filipino Women, Migration, and Violence in Australia:Lived Reality and Media Image. Kasarinlan. Philippine Journal of Third World Studies, 21(1), 75-100.

Soriano, C., Lim, S.S. \& Rivera-Sanchez, M. (2016), 'The Virgin Mary with a mobile phone: Ideologies of mothering and technology consumption in Philippine television advertisements', Communication, Culture \& Critique, 8(1), 1-19.

Tolentino, R. (1996). Bodies, letters, catalogs: Filipinas in transnational space. Social Text (48), 49-76. doi:10.2307/466786

WeAreSocial (2019). Global 2019: Global Internet use accelerates. Retrieved from https://wearesocial.com/blog/2019/01/digital-2019-global-internet-use-accelerates Winch, A. (2013). Girlfriends and Postfeminist Sisterhood. Basingstoke: Palgrave Macmillan. 